\title{
Pharyngeal Stripping Wave Absent
}

National Cancer Institute

\section{Source}

National Cancer Institute. Pharyngeal Stripping Wave Absent. NCI Thesaurus. Code C127313.

A finding of an absent pharyngeal stripping wave. 